\title{
Balkanologie
}

Balkanologie Revue d'études pluridisciplinaires

Vol. VIII, $n^{\circ} 1 \mid 2004$

Volume VIII Numéro 1

\section{Bozarslan (Hamit), Histoire de la Turquie contemporaine}

Paris : La Découverte (collection « Repères »), 2004,123 p.

\section{Hervé Geoigelin}

\section{OpenEdition}

\section{Journals}

Édition électronique

URL : http://journals.openedition.org/balkanologie/2093

DOI : 10.4000/balkanologie.2093

ISSN : 1965-0582

\section{Éditeur}

Association française d'études sur les Balkans (Afebalk)

Édition imprimée

Date de publication : 1 juin 2004

ISSN : 1279-7952

\section{Référence électronique}

Hervé Geoigelin, « Bozarslan (Hamit), Histoire de la Turquie contemporaine », Balkanologie [En ligne], Vol.

VIII, $n^{\circ} 1$ | 2004, mis en ligne le 21 janvier 2010, consulté le 17 décembre 2020. URL : http://

journals.openedition.org/balkanologie/2093; DOI : https://doi.org/10.4000/balkanologie.2093

Ce document a été généré automatiquement le 17 décembre 2020.

(c) Tous droits réservés 


\section{Bozarslan (Hamit), Histoire de la Turquie contemporaine}

Paris : La Découverte (collection « Repères »), 2004,123 p.

Hervé Geoigelin

\section{RÉFÉRENCE}

Bozarslan (Hamit), Histoire de la Turquie contemporaine, Paris : La Découverte (collection « Repères »), 2004,123 p.

1 C'est, à mon sens, un outil fondamental que nous offre H. Bozarslan, une introduction à l'histoire d'un pays déconcertant, qui, hier « quintessence » de l'Orient, est aujourd'hui candidat à l'intégration dans l'Union Européenne, unique pays industrialisé au ProcheOrient, dont le régime possède certains traits de la démocratie parlementaire. Il y a, habituellement, bien des mauvaises raisons d'admirer ce pays : nombre de Français veulent y voir un doublon de leur République nationale, laïque, moderniste et unitaire (ellemême pourtant mal en point) et d'une façon générale, des Occidentaux, nostalgiques de l'époque des grands chefs suprêmes, sont fascinés par la stature démiurgique de Mustafa Kemal Atatürk, campé dans le rôle de modernisateur-fondateur. Or rien de tout cela dans l'ouvrage de Bozarslan. Concision et démythification dictent ici le propos. Prenant à rebrousse-poil le mythe d'une Turquie républicaine émergée, comme par miracle, des fonds de l'histoire ottomane, Bozarslan présente la création de la Turquie moderne non pas en termes de rupture, mais en continuité avec le mouvement jeune-turc, réinsérant Mustafa Kemal dans sa genèse historique, (pp. 24-25.) Il repense ainsi la chronologie de la Turquie contemporaine, dans un geste ambitieux et stimulant.

2 L'approche proposée tient à la fois de l'histoire politique et de l'histoire sociale. Loin de centrer son propos sur les épiphénomènes, Bozarslan saisit les interactions entre vie politique formalisée et les évolutions de la société turque. Des incursions dans le domaine culturel stricto sensu esquissent une approche qui dépasse les clivages 
disciplinaires. (De toute évidence, Bozarslan aime les livres d'Orhan Pamuk!) Les références indiquées, nombreuses pour un ouvrage si concis, renouvellent la bibliographie standard : Étienne Copeaux, Selim Deringil, Vahakn Dadrian et Erich-Jan Zürcher, pour ne retenir que quatre noms, ne peuvent plus être ignorés du grand public.

3 Cette synthèse ne voile pas les pages sombres de la modernité ottomane, les massacres arméniens des années 1894-1896, (p. 9) et le génocide arménien de 1915 sont dûment évoqués (p. 18), ainsi que les distorsions historiographiques officielles (p. 20), trop souvent encore relayées en Occident. L'ambiguïté, pour le moins, de la Turquie pendant la Seconde Guerre mondiale, est également exposée. L'auteur analyse aussi la violence étatique récurrente, déployée à rencontre de toutes les populations non turques et non sunnites. La forte coercition est un des traits majeurs du mode de gouvernement du pays, à l'époque contemporaine. Et en même temps, la société turque secrète avec vigueur de nombreuses dissidences ou résistances qui font du pays vivant, un ensemble bien plus intéressant, que les chromos que l'on nous assène habituellement.

Bozarslan est, de toute évidence, bienveillant envers son objet d'étude, alors qu'il est aussi spécialiste de l'histoire kurde ${ }^{1}$. Sa conclusion est celle d'un optimiste prudent : il n'y a pas de fatalité à la spirale de la violence turque (p. 106). Il suggère à la Turquie de «faire société » et de renoncer à la doctrine de la nation organique, perpétuellement mise en danger par des ennemis extérieurs, mais surtout intérieurs. Bozarslan pense que le moment historique est favorable à une telle mutation, toutefois ses propositions laissent un peu rêveur : reconnaissance des divers groupes humains existant ou ayant existé en Turquie, décentralisation, modestie de l'État et de l'armée qui devraient abandonner leur rôle normatif. On pense au programme des Libéraux ottomans (p. 11), toujours évoqués mais bien peu écoutés. On peut penser aussi à des visions postmodernes de l'État prétendument «neutre ", dont on peut se demander quels seraient les résultats, notamment en termes de laïcité, et pas seulement en Turquie.

\section{NOTES}

1. Bozarslan (Hamit), La question kurde: États et minorités au Moyen-Orient, Paris: Presses de Sciences Po, 1997. 